\title{
Results of Local Recurrence in Patient with Breast Ductal Carcinoma In situ and Comparison with Low-Risk Groups in ECOG 5194 Study
}

\section{Meme Duktal Karsinoma In Situ Tanılı Olgularda Lokal Rekürrens Sonuçları ve ECOG 5194 Çalışmasındaki Düşük Riskli Gruplar ile Karşılaştırılması}

\author{
Özlem Özkaya Akagündüz ${ }^{1}$, Didem İkiz ${ }^{1}$, Burcu Akbelen ${ }^{2}$, Senem Alanyalı ${ }^{1}$, Ayfer Haydaroğlu ${ }^{1}$, Arif \\ Aras $^{1}$, Zeynep Özsaran ${ }^{1}$
}

${ }^{1}$ Ege Üniversitesi Tıp Fakültesi Radyasyon Onkolojisi Anabilim Dalı, İzmir, Türkiye

${ }^{2}$ Atatürk Eğitim ve Araştırma Hastanesi, Radyasyon Onkolojisi Bölümü, İzmir, Türkiye

\begin{abstract}
ÖZET
GÍRIŞ ve AMAÇ: Bu çalışmada, duktal karsinoma in situ (DKİS) tanılı hastalarda meme koruyucu cerrahi (MKC) ve adjuvan radyoterapi (RT) sonrası lokal yineleme sonuçları, prognostik faktörler araştırılmış ve Eastern Cooperative Oncology Group (ECOG) E5194 çalışması ile karşılaştııılmıştır.

YÖNTEM ve GEREÇLER: DKİS tanısı 96 hasta geriye dönük olarak değerlendirilmiştir. Lokal kontrolü etkileyen prognostik faktörler (yaş, tümör boyutu, cerrahi sınır, nükleer grad, komedo nekroz varlığı, reseptör durumu) araştırılmış ve ECOG E5194 çalışmasına göre tanımlanmış olan düşük riskli gruplar, lokal kontrol açısından karşılaştırılmıştır.
\end{abstract}

BULGULAR: Hastalar ortanca 62 ay (8-139) ay takip edilmiştir. Hastalık yinelemesi 5 hastada gelişmiş: 2 (\%2.1)'si invaziv meme karsinomu, 3’ü (\%3.1) DKİS'dir. On yıllık lokal kontrol \%89 olmuştur. Lokal hastalık yinelemesinde 50 yaşın altı, Östrojen (ER) reseptör negatifliği, c-erb-B2 pozitifliği anlamlı bulunmuștur (sırasıyla $\mathrm{p}=0.020, \mathrm{p}=0.014, \mathrm{p}=0.022$ ). 50 yaş altı için alt grup analizi yapılmış: ER negatifliği ve c-erb-B2 pozitifliği lokal yinelemeyi arttıran faktörler olmuştur (sırasıyla $\mathrm{p}=0.024, \mathrm{p}=0.046$ ). ECOG çalışmasına göre düşük riskli grup olarak kabul edilen Grup 1 ve Grup 2 ve bu iki grup ile bu iki gruba dahil olmayanlar karşılaştırılmış; her iki karşıılaştırmada fark saptanmamışıır ( $\mathrm{p}>0.05)$.

TARTIŞMA ve SONUÇ: DKİS'da lokal kontrolü etkileyen prognostik faktörler yaş ve hormon reseptör durumu olmuştur. ECOG çalışmasına göre tanımlanmış düşük riskli gruplarda adjuvan RT eklenmesinin 10 yılda mutlak olarak \%10 katkı sağlamıştır.

Anahtar Kelimeler: DKİS, Radyoterapi, Lokal kontrol, Prognostik faktörler

\begin{abstract}
INTRODUCTION: In this study, local recurrence rates and prognostic factors was investigated in patients with ductal carcinoma in situ (DCIS) after breast conserving surgery (BCS) and adjuvant radiotherapy (RT) and compared with Eastern Cooperative Oncology Group (ECOG) Study E5194.

METHODS: Totally 96 patients were evaluated retrospectively. Prognostic factors that might influence local control (age, tumor size, surgical margins, nuclear grade, comedo necrosis, hormone receptor status) were investigated. The eligibility criteria of ECOG 5194 were stratified into two groups as in the original study and were compared for local control.

RESULTS: The median follow-up time was 62 ay (8-139) months. Local recurrence was observed in 5 patients who had 2 (\%2.1) invasive carcinoma and 3 (\%3.1) DCIS. Ten years local control rate was 89\%. In the recurrence of local disease, the age of 50 years, estrogen (ER) receptor negativity, c-erb-B2 positivity was found to be significant (respectively $\mathrm{p}=0.020, \mathrm{p}=0.014, \mathrm{p}=0.022$ ). According to the $\mathrm{ECOG}$ study, Group 1 and Group 2 , which are considered to be low risk groups, and these two groups were compared with those who were not included in these two groups; there was no difference in both comparisons ( $p>0.05$ ).

DISCUSSION AND CONCLUSION: Prognostic factors affecting local control in DCIS have been age and hormone receptor status. When 10-year results were compared with the ECOG 5194, adjuvant RT produced an absolute difference of $10 \%$ in low-intermediate and high grade in local control.
\end{abstract}

Keywords: DCIS, Radiotherapy, Local control, Prognostic factor 


\section{GİRIŞ}

Meme kanserinin non-invaziv formu olan duktal karsinoma in situ (DKİS) (1) meme kanserinin yaklaşık \%30'nu oluşturur (2). DKİS'de tedavi, mastektomi veya meme koruyucu cerrahi ve adjuvan radyoterapi (RT) olup; tedavide amaç, iyi bir meme kozmetiği ile birlikte in situ ve invaziv meme kanseri riskini azaltmaktır (3). Bu nedenle günümüzde meme koruyucu tedavi DKİS' da kabul görmüş tedavi yöntemidir (4,5). Lokal rekürrens için, DKİS'nin histopatolojik ve klinik karakteri ile ilgili yüksek grad, tümör boyutu, cerrahi sınır yakınlığı, komedo nekroz varlığı, hastanın yaşının $<50$ olması gibi birçok prognostik faktör ortaya konulmuş olsa da (6), DKİS heterojen bir hastalıktır ve hiçbirinin aynı şekilde seyretmesi beklenmez (7). Birçok randomize çalışmada meme koruyucu cerrahi (MKC)'ye RT eklenmesinin ipsilateral memede in situ veya invaziv tümör rekürrens gelişmesini yaklașık \%50 oranında azalttığı gösterilmiș (811) olsa da, hastalık yinelemesini öngörecek bir konsensus oluşturulmamıştır (7).

Eastern Cooperative Oncology Group (ECOG)'un ECOG-ACRIN E5194 çalışması DKİS tanılı hastalarda RT'nın gerekli olmadığı düşük risk grubunu araştırmak için yapılmış, çok merkezli, prospektif, tek kollu bir çalışmadır. Düşük-orta grad (LIG) ve yüksek grad (HG)'li olup 'düşük riskli' olarak tanımlanmış olan 2 DKİS grubu, adjuvan RT yapılmadan izlenmiş, 12 yıllık lokal yineleme sonuçları sırasıyla \%14.4, \%24.6 olarak bulunmuștur (12).

Çalışmamızda, DKİS tanılı hastalarda meme koruyucu cerrahi ve adjuvan RT sonras1 lokal yineleme sonuçları, prognostik faktörler araştırılmış ve ECOG 5194 çalışmasına göre tanımlanmış olan 'düşük riskli gruplar'ın bu çalışmada adjuvan RT eklenmesi ile sonuçları özgün çalışma ile karşılaştırılmıştır.

\section{GEREÇ-YÖNTEM:}

Ege Üniversitesi Radyasyon Onkolojisi Anabilim Dalı'nda DKİS tanısı ile Ocak 2000Aralık 2014 arasında RT uygulanan 96 olgu geriye dönük olarak değerlendirilmiștir. Mikroinvaziv ve invaziv tümörler çalışmaya dahil edilmemiştir. Hasta özellikleri, tümör boyutu, cerrahi sınır, nükleer grad, komedo nekroz varlığı, reseptör durumu ve tedavi şekli hasta dosyalarından elde edilmiștir. Tümör histopatolojilerinin değerlendirilmesi, meme patolojisi konusunda deneyimli patologlar tarafından yapılmıştır.

Tüm memeye yönelik adjuvan RT, günlük fraksiyonu 2 Gy'den total 50 Gy uygulanmış, ancak yüksek riskli olgularda (cerrahi sınır yakınlığı / pozitifliği ve 40 yaş altı olanlar) total doz, tümör yatağına boost ile 6066 Gy'e yükseltilmiştir. RT planlamasında doz homojenitesini sağlamak için dinamik wedge, field-in-field tekniği kullanılmış, IMRT yapılan hastalarda forward tedavi tekniği uygulanmıștır.

ECOG E5194 çalışmasına göre düşük risk grubu 2 şekilde tanımlanmış; Grup 1: cerrahi sınır $>3 \mathrm{~mm}$, düşük-orta grad DKİS, tümör $\leq 2.5 \mathrm{~cm}$, Grup 2: cerrahi sınır $>3 \mathrm{~mm}$, yüksek grad DKİS, $\leq 1 \mathrm{~cm}$ tümör boyutu olan hastalardır.

Olgular ilk 5 y1l 6 ay'da bir, sonrasında yılda 1 takip ile devam edilmiş, ulaşılabilen takipsiz hastaların klinik ve radyolojik ipsilateral ve kontralateral memede in situ veya invaziv kanser açısından değerlendirmesi yapılmış, ulaşılamayan hastalarda son değerlendirme kaydedilmiștir. Çalışmada tedavi bașlangıcından yineleme tarihi veya son kontrole kadar geçen süre lokal kontrol süresi olarak değerlendirilmiştir. İstatistik analizi için Predictive Analytic Software (PASW) Version 18.0.A kullanılmış ve $p<0.05$ anlamlı kabul edilmiştir. Lokal kontrol süresi ve oranları Kaplan-Meier sağkalım analiz yöntemi ile hesaplanmıştır. Lokal kontrole etki eden faktörlerin tek değişkenli analizi (hasta yaşı, nükleer grad, komedo nekroz durumu, cerrahi sinır, tümör boyutu, hormon reseptörleri ve ECOG çalışmasına göre Grup 1 ve Grup 2) için karşı1laştırma Pearson Chi Square testi ile yapılmış, beklenen sayıların 5'den küçük olmas1 (expected frequencies) durumunda Fisher's Exact testi uygulanmış ve risk faktörlerinin ipsilateral meme nüksü için odds oranı crosstabulation ile belirlenmiştir. 


\section{BULGULAR}

\section{Hasta, tümör ve tedavi özellikleri:}

Olguların ortanca yaşı 50 ve \%48'i premenapozaldir. Hastaların histopatolojik incelemesinde $\% 38$ olguda yüksek grad mevcut olup, komedo nekroz saptanmayan olgular çoğunluktadır (\%67). Olguların \%34'ünde tümör boyutu $10 \mathrm{~mm}$ üzerindedir ve $\% 42$ 'sinde cerrahi sınır 5mm'nin altındadır. Reseptör durumu değerlendirildiğinde ER pozitifliği $\% 67$, c-erb-B2 reseptörü pozitifliği \%37 olguda izlenmiştir. Olguların \%81'i tamoksifen kullanmıştır. ECOG E5194 kriterlerine 55 hasta uygun bulunmuştur: Grup 1'de hastaların \%42'si, Grup 2'de \%13'ü yer almıştır. Ayrıntılı bilgi tablo 1'dedir.

Tablo 1. Hasta özellikleri

\begin{tabular}{|c|c|c|c|}
\hline & & Hasta (n) & Yüzde (\%) \\
\hline Takip süresi (ortanca-ay) & $62(8-139)$ & & \\
\hline Yaş (ortanca-yıl) & $50(24-75)$ & 96 & 100 \\
\hline \multirow[t]{3}{*}{ Menapoz durumu } & Pre-perimenapozal & 46 & 48 \\
\hline & Postmenapozal & 49 & 51 \\
\hline & Bilinmeyen & 1 & 1 \\
\hline \multirow[t]{4}{*}{ Nükleer grad } & I & 26 & 27 \\
\hline & II & 34 & 35 \\
\hline & III & 36 & 38 \\
\hline & Bilinmeyen & 1 & 1 \\
\hline \multirow[t]{5}{*}{ Cerrahi sınır } & $<1 \mathrm{~mm}$ & 10 & 11 \\
\hline & $1-4,9 \mathrm{~mm}$ & 29 & 31 \\
\hline & $5-9,9 \mathrm{~mm}$ & 21 & 22 \\
\hline & $\geq 10 \mathrm{~mm}$ & 32 & 33 \\
\hline & Bilinmeyen & 3 & 3 \\
\hline \multirow[t]{3}{*}{ Tümör boyutu } & $\leq 5 \mathrm{~mm}$ & 37 & 39 \\
\hline & $6-10 \mathrm{~mm}$ & 26 & 27 \\
\hline & $>10 \mathrm{~mm}$ & 33 & 34 \\
\hline \multirow[t]{3}{*}{ ECOG 5194} & Grup 1 & 42 & 42,5 \\
\hline & Grup 2 & 13 & 13 \\
\hline & Diğer & 41 & 44,5 \\
\hline \multirow[t]{3}{*}{ Östrojen reseptörü } & Pozitif & 64 & 65 \\
\hline & Negatif & 22 & 23 \\
\hline & Bilinmeyen & 10 & 11 \\
\hline \multirow[t]{3}{*}{ Progesteron reseptörü } & Pozitif & 58 & 60 \\
\hline & Negatif & 28 & 30 \\
\hline & Bilinmeyen & 10 & 10 \\
\hline \multirow[t]{3}{*}{ C-erb-B2 reseptörü } & Pozitif & 35 & 36,5 \\
\hline & Negatif & 38 & 39,5 \\
\hline & Bilinmeyen & 23 & 20 \\
\hline
\end{tabular}


Tablo 2. Lokal yineleme gelișen hastaların klinik ve histopatolojik özellikleri

* Grup 1 ve 2'de yer almayanlar

\begin{tabular}{lcccccccccccc}
\hline Hasta & Yaş & Menapoz & $\begin{array}{c}\text { Nekroz } \\
\text { tipi }\end{array}$ & $\begin{array}{c}\text { Nükleer } \\
\text { grad }\end{array}$ & $\begin{array}{c}\text { Cerrahi } \\
\text { sinır } \\
(\mathbf{m m})\end{array}$ & $\begin{array}{c}\text { Tümör } \\
\text { capi } \\
(\mathbf{m m})\end{array}$ & $\begin{array}{c}\text { ER } \\
\text { Cerb- }\end{array}$ & $\begin{array}{c}\text { Grup } \\
\text { B2 }\end{array}$ & $\begin{array}{c}\text { RT } \\
\text { dozu }\end{array}$ & $\begin{array}{c}\text { Yineleme } \\
\text { histopatolojisi }\end{array}$ & $\begin{array}{c}\text { Yineleme } \\
\text { süresi } \\
\text { (ay) }\end{array}$ \\
\hline $\mathbf{1}$ & 35 & pre & $\begin{array}{c}\text { Non- } \\
\text { komedo }\end{array}$ & 3 & 4 & 17 & - & + & $*$ & 60 & DKIS & 60 \\
$\mathbf{2}$ & 48 & pre & Komedo & 3 & 10 & 3 & - & + & 2 & 50 & DKIS \\
$\mathbf{3}$ & 46 & post & Komedo & 3 & 1 & 29 & + & + & $*$ & 66 & DKIS & 77 \\
$\mathbf{4}$ & 43 & pre & $\begin{array}{c}\text { Non- } \\
\text { komedo }\end{array}$ & 2 & 2 & 10 & - & + & $*$ & $\begin{array}{c}60 \\
\text { Gy }\end{array}$ & $\begin{array}{c}\text { Invaziv } \\
\text { karsinom } \\
\text { Invaziv } \\
\text { karsinom }\end{array}$ \\
$\mathbf{5}$ & 49 & pre & Komedo & 3 & 1 & 26 & - & + & $*$ & $\begin{array}{c}60 \\
\text { Gy }\end{array}$ \\
\hline
\end{tabular}

\section{Tedavi sonuçları ve prognostik faktörler:}

MKC sonras1 adjuvan RT uygulanan DKIS tan1lı hastalar, ortanca 62 (8-139) ay takip edilmiştir. Lokal yineleme ortanca 62 ay (6-97 ay) sonra: 2 (\%2.1)'sinde meme karsinomu, 3 (\%3.1)'ünde DKİS şeklinde olup toplam 5 (\%5.2) hastada geliş̧miştir. Beş ve 10 yıllık lokal kontrol sirasiyla $\% 95.9$ ve $\% 89.5$ olmuştur.

Lokal hastalık yinelemesini etkileyen faktörler açısından değerlendirildiğinde, yaşın 50'nin altında olmas1, ER negatifliği, c-erb-B2 pozitifliği meme yineleme riski açısından anlamlı fark bulunmuştur (sırasıyla odds $=0.88$ \%95 GA (Güven Aralığı) 0.802-0.986, $p=0.020$, odds $=0.71 \% 95$ GA $0.008-0.68$, $p=0.014$; odds $=1.167 \% 95$ GA 1.019-1.336, $p=0.022$ ) (Resim 1). Yüksek nükleer grad'l1 olgularda yineleme riskinde artma eğilimi olmakla birlikte fark gösterilememiştir $(p=0.066)$. Nekroz tipi, cerrahi sınır yakınlığ tümör çapının $1 \mathrm{~cm}$ üzerinde olması lokal yineleme açısından anlamlı bulunmamıştır. ECOG çalışmasına göre düşük riskli grup olarak kabul edilen Grup 1 ve Grup 2 ve bu iki grup ile bu iki gruba dahil olmayanlar karşılaştırılmış; her iki karşılaştırmada fark saptanmamıştır ( $p>0.05$ ), Grade 3 olup ECOG Grup 2 'ye dahil olanlar ile grup dişı kalanlar karşılaştırılmış ve anlamlı fark bulunmamıştır $(p=0.69) \quad$ (Sirasiyla Resim 2 ve 3 'de gösterilmiş̧tir).

Tüm lokal yinelemelerin 50 yaş altı kadınlarda olması nedeniyle bir alt grup analizi yapılmış ve buna göre; ER negatifliği ve c-erbB2 pozitifliği yineleme riski açısından anlamlı bulunmuştur (sırasılyla odds $=0.78 \% 95$ GA $0.008-0.786, p=0.024$, odds $=1.357 \% 95$ GA $1.037-1.776, p=0.046)$. Nükleer grad'1 yüksek olan olgularda lokal yineleme riski artma eğiliminde olmakla birlikte anlamlı fark bulunmamıştır $(p=0.060)(\operatorname{Resim} 4)$.

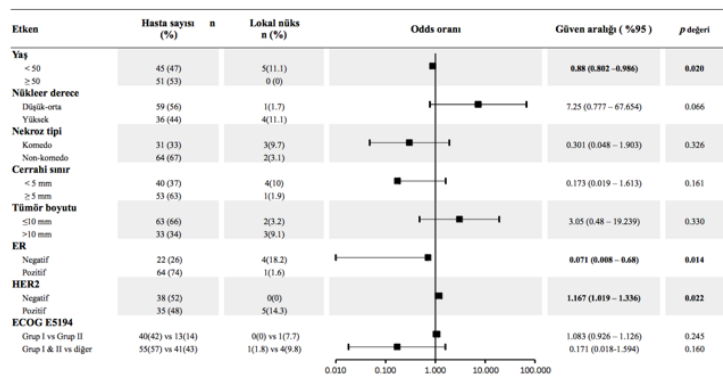

Resim 1. DKİS için klinik ve histopatolojik özelliklerin lokal yinelemede prognostik açıdan karşılaştırma Pearson Chi Square testi ile yapılmış ve risk faktörlerinin ipsilateral meme yinelemesi için odds oranı crosstabulation ile belirlenmiştir. 


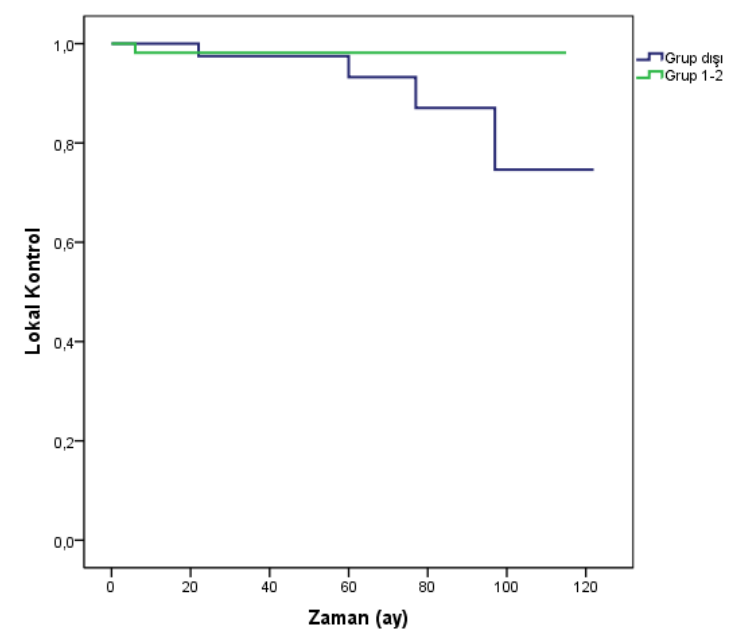

Resim 2. ECOG Grup 1-2 ile hiçbir gruba dahil olmayan olguların lokal kontrol karşılaştırması. (5 yıllık lokal kontrol oran1 Grup 1-2 ve gruba dahil olmayanlar için sirasıyla $\% 98$ vs. $\% 93,3 ; 7$ y1llık lokal kontrol oran1 $\% 98$ vs. $\% 87 \mathrm{p}=0.124$ )

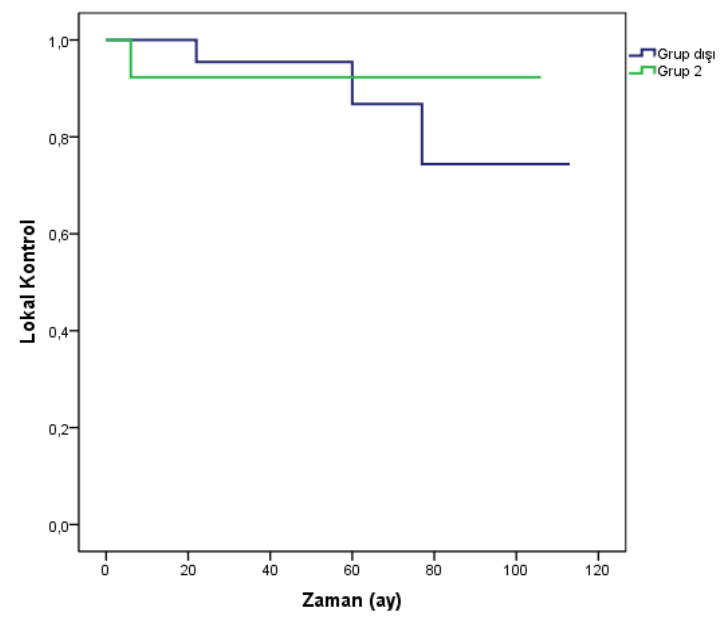

Resim 3. Grade 3 olup ECOG Grup 2 'ye dahil olanlar ile grup dışı kalan olguların lokal kontrol karşılaştırması. (5 y1llık lokal kontrol oran1 Grup 2 ve gruba dahil olmayanlar için sırasıyla $\% 92,3$ vs. $\% 86,8 ; 7$ yıllık lokal kontrol oranı $\% 92,3$ vs. $\% 74,4 \mathrm{p}=0.69$ )

ECOG E5194 çalışmasında tanımlanan düşük riskli gruplarda adjuvan RT sonrası takipte Grup 1'de lokal yineleme gözlenmezken, Grup 2'de $1 \quad(\% 7.7)$ olguda lokal yineleme gelişmiştir; diğer 4 hastadaki yineleme, ECOG risk gruplarına dahil olmayan olgularda izlenmiştir. Grup 1'de lokal yineleme gelişmemekle birlikte, 10 yıllık lokal yineleme Grup 2' de \%7.7 bulunmuştur. ECOG E5194 çalışmasında ise aynı sonuçlar Grup 1'de 12 yıl için \%14.4, Grup 2'de \%24.6 olmuştur. Adjuvan RT'nin uygulanmadığı ECOG E5194 çalışması ile adjuvan RT'nin uygulandığı Ege Üniversitesi ve Motwani (13) çalışmalarının karşılaştırmaları tablo 3'de yer verilmiştir.

\section{TARTIŞMA}

Çalışmamızda, DKİS nedeniyle adjuvan RT uygulanmış hastalarda lokal kontrol sonuçları ve lokal kontrolü etkileyen prognostik faktörler araştırılmıştır. DKİS tanılı 96 hasta medyan 50 ay takip edilmiş ve sırasıyla 5 ve 10 yıllık lokal yineleme oran $1 \% 4$ ve $\% 10.5$ bulunmuştur. DKIS'da MKC sonras1 RT'nin rolü hala tartışmalıdır. Dört büyük prospektif randomize klinik çalışmanın (NSABP B-17, EORTC 10853, SWE-DCIS, UK/ANZ) değerlendirildiği meta-analizde; adjuvan RT'nin ipsilateral memede invaziv kanser ve karsinoma in-situ olaylarını \%60 azalttığını bildirilmiştir. $\mathrm{Bu} 4$ prospektif randomize çalışmada RT ve gözlem kollarında tüm risk grubundaki hastalar yer aldığı için RT'nin gerekli olmayacağı bir alt-grup varlığını tanımlayamamış ancak lokal yineleme riskinin daha yüksek olduğu özellikle genç hastalarda, yüksek grad'lı tümörlerde ve pozitif cerrahi sınırda adjuvan RT'nin rolünün önemli olduğu vurgulanmıştır (14). EORTC 10853 çalışmasının 10 yıllık sonuçlarında adjuvan RT eklenmesi ile lokal yineleme oranları \%26'lardan \%15'lere düşmüştür (10). Early Breast Cancer Trialists' Collaborative Group'un meta-analizinde 10 yılda RT'nin ipsilateral meme de insitu veya invaziv kanser gelişmesinde mutlak riski $\% 15.2$ azalttığ bildirilmiştir (15).

Lokal yinelemeyi etkileyen olumsuz faktörler çalışmamızda, yaşın 50'nin altında olmas1, ER negatifliği ve c-erb-B2 pozitifliği bulunmuştur. Tüm lokal yinelemelerin 50 yaş altı kadınlarda gelişmesi nedeniyle, 50 yaş altı için alt grup analizi yapılmış; c-erb-B2 reseptör pozitifliği, ER negatifliğinin önemli prognostik faktörler olduğu saptanmıştır. Tümör çapının $1 \mathrm{~cm}$ üzerinde olması, cerrahi sinırın $5 \mathrm{~mm}$ 'den yakın olması, komedo nekroz varlığ yinelemeyi etkileyen faktörler açısından anlamlı bulunmamıştır. Ontario DKİs Cohort çalışmasında meme koruyucu cerrahinin yeterli olabileceği düşük riskli grubun araştırıldığ çalışmada (16) negatif cerrahi sınırlı yalnızca 
meme koruyucu cerrahi yapilan 571 hastada lokal yineleme için prediktif faktörlerin multifokal tümör varlığı, tümör boyutunun $1 \mathrm{~cm}$ üzerinde olmas1, 50 yaş altı, solid histopatoloji, komedo nekroz varlığı, yüksek grad olarak gösterilmiştir. Bu prognostik faktörlerle birlikte gen profil analizi geliştirilerek meme koruyucu cerrahi sonrası lokal yinelemeyi öngörecek edecek skorlama sistemi oluşturulmuştur. Diğer bir prognostik skorlama çalışmasında ise, SEER verilerinden elde edilmiş 32,144 RT uygulanan ve uygulanmayan hastanın değerlendirildiği çalışmada adjuvan RT'nin katkısı araştırılmış; yüksek nükleer grad, genç hasta, büyük tümör boyutunda RT'nin yalnizca lokal kontrolde değil aynı zamanda sağkalımda da avantaj sağladığ1 gösterilmiş ve doğrulamas1 yapılmış olan prognostik skorlama sistemi geliştirilmiştir (17).

DKIS'de her ne kadar adjuvan RT ile hastaların yaklaşık yarısında yineleyen hastalık önlenebilse de radyoterapinin en fazla yarar sağladığı grubun tanımlanması ile ilgili belirsizlikler devam etmekte, düşük ve yüksek riskli hastalıkta RT'nin fayda ve zarar dengesi oldukça değişkenlik gösterebilmektedir (14). DKİS tanısı almış bir kısım hastada adjuvan RT'nin fazla tedavi edici olduğu görüşü de mevcuttur (18). RT'nin gerekli olmayacağ 1 klinik ve patolojik olarak olumlu hasta grubunu tanımlamak için yapılmış tek kollu nonrandomize prospektif çalışma olan ECOGACRIN E5194'da (12) düşük riskli 2 alt grup tanımlanmış: en az $3 \mathrm{~mm}$ cerrahi sınırı olan, $1 \mathrm{~cm}$ ve altında tümör boyutlu, yüksek grad'li grupta 12 y1llık ipsilateral meme yineleme oranları \%24,6 bulunmuştur. Bu grup'ta adjuvan RT'nin gerekli olduğu düşünülmüştür. Grup 1 'de düşük ve orta grad' $11,2,5 \mathrm{~cm}$ ve altında tümör boyutlu, cerrahi sınır $3 \mathrm{~mm}$ ve üzeri olan hastalar değerlendirilmiş, 12 yıllık sonuçlarında ipsilateral yineleme \%14,4 bulunmuştur. $\mathrm{Bu}$ çalışmanın en önemli dezavantajının bu olumlu gruplar için RT kolunun olmaması nedeniyle sonuçların karşılaştırılamamasıdır. Çalışmamızda da ECOG çalışmasındaki Grup 1 ve 2'deki hasta özellikleri tanımlanmış ve adjuvan RT sonrası lokal kontrol sonuçları bildirilmiştir. Grup 2'de 1 hastada lokal yineleme gelişmiştir. ECOG çalışmasındaki riskler tanımlanıp adjuvan RT uygulanmış olan Montwani'nin retrospektif çalışmasında (13) 7 yıllık lokal yineleme oranları Grup 1 için \%4,4, Grup 2 için \%2.0 saptanmıştır. DKİS'de düşük risk olarak tanımlanmış olan grup için RT ve gözlem kolunun karşılaştırıldığ ilk prospektif randomize çalışma olan RTOG 9804'da düşükorta grad, $2.5 \mathrm{~cm}$ altında tümör boyutu ve $3 \mathrm{~mm}$ ve alt1 cerrahi sinirlı 636 hasta değerlendirilmiştir. Yedi yıllık sonuçlarda RT kolunda $\% 0,9$, gözlem kolunda \%6.7 lokal yineleme gelişmiştir $(p<0.001)$. Düşük riskli olarak tanımlanmış olan bu grup için, gözlem kolu her ne kadar lokal yineleme açısından anlamlı yüksek bulunsa da bu çalışma yalnızca lumpektominin yeterli olabileceği konusunda yol gösterici olmuştur. Ancak ECOG çalışmasındaki 12 yıllık sonuçları ile karşılaştırıldığında düşük-orta grad grubunda lokal yinelemelerin geç dönemde olduğu ve uzun dönem sonuçlarının daha belirleyici olacağ1 vurgulanmıştır (19).

Sonuç olarak, prospektif randomize çalışmalar DKIS'de adjuvan RT'nin ipsilateral meme yinelemelerini $\quad \% 60$ azalttığını göstermiştir. Çalışmamızda 10 yıllık lokal kontrol oran1 \%89'dur. Lokal kontrolü etkileyen önemli prognostik faktörlerden biri, yaş olmuştur. Elli yaş altı kadınlar değerlendirildiğinde ER negatifliği, c-erb-B2 pozitifliği lokal yinelemeyi olumsuz etkileyen faktörler olarak değerlendirilmiştir. ECOG 5194 çalışması ile 7 yıllık sonuçlar karşılaştırıldığında adjuvan RT lokal kontrol sağlama açısından düşük-orta grad'da $\% 10.5$, yüksek grad'da \%10.3 mutlak fark oluşturmuştur. İyi tanımlanmış düşük riskli hasta gruplarını belirleyip adjuvan RT'nin uygulanmayacağı popülasyon için çalışmalar devam etmektedir (20-22). Ancak DKIS'in doğasının oldukça heterojen olduğunu göz önünde bulundurursak RT'nin gerekmeyeceği hastaları belirleyebilmek için klinik ve patolojik özelliklerin yanında moleküler belirteçler daha çok önem kazanacaktır.

\section{Çıkar Çatışması: Yok}

\section{KAYNAKLAR}

1. Ernster VL, Ballard-Barbash R, Barlow WE, et al. Detection of ductal carcinoma in situ in women undergoing screening mammography. J Natl Cancer Inst 2000;94:1546-1554.

2. Jemal A, Siegel R, Ward E, Hao Y, Xu J, Thun MJ. Cancer statistics. CA Cancer J Clin. 2009;59:225249.

3. Schwartz GF, Solin LJ, Olivotto IA, Ernster VL, Pressman PI. The consensus conference on the 
treatment of in situ ductal carcinoma of the breast. Hum Pathol 2000;31:131-139.

4. Arnesson LG, Olsen K. Linko"ping experience. In: Silverstein MJ, editor. Ductal carcinoma in situ of the breast (section VII: Excision only). Baltimore: Williams \& Wilkins; 1997 p. 373-377.

5. Ottesen GL, Graversen HP, Blichert-Toft M, et al. Carcinoma in situ of the female breast: 10-year follow-up results of a prospective nation-wide study. Breast Cancer Res Treat 2000;62:197-210.

6. Early Breast Cancer Trialists' Collaborative Group [EBCTCG]. Overview of the randomized trial of radiotherapy in duct carcinoma in situ of the breast. $\mathrm{J}$ Natl Cancer Inst Monog 2010;41:162-77.

7. Bleicher RJ. Duct carcinoma in situ. Surg Clin N Am 2013;93:393-410.

8. Fisher B, Land S, Mamounas E, Dignam J, Fisher E.R, Wolmark N. Prevention of invasive breast cancer in women with ductal carcinoma in situ: an update of the national surgical adjuvant breast and bowel project experience, Semin Oncol 2001;28:400-418.

9. EORTC Breast Cancer Cooperative Group; EORTC Radiotheapy, N. Bijker, P. Meijnen et al., Breastconserving treatment with or without radiotherapy in ductal carcinoma-insitu: ten-year results of european organisation for research and treatment of cancer randomized phase III trial 10853-A study by the EORTC breast cancer cooperative group and EORTC radiotherapy group, J Clin Oncol 2006;24:33813387.

10. Holmberg L, Garmo H, Granstrand B, et al. Absolute risk reductions for local recurrence after postoperative radiotherapy after sector resection for ductal carcinoma in situ of the breast. J Clin Oncol 2008;26:1247-1252.

11. Houghton J. Radiotherapy and tamoxifen in women with ompletely excised ductal carcinoma in situ of the breast in the UK, Australia, and New Zealand: randomised controlled trial, Lancet 2003;362:95102.

12. Solin LJ, Gray R, Hughes LL, et al. Surgical Excision Without Radiation for Ductal Carcinoma in Situ of the Breast: 12-Year Results From the ECOG-ACRIN E5194 Study. J Clin Oncol 2015;33:3938-44
13. Motwani SB, Goyal S, Moran MS, Chhabra A, Haffty BG. Ductal Carcinoma In Situ Treated With BreastConserving Surgery and Radiotherapy: A Comparison With ECOG Study 5194. Cancer 2011;117:1156-1162.

14. Fortunato L, Poccia I, de Paula U, Santini E. Ductal Carcinoma In Situ:What CanWe Learn from Clinical Trials? Int J Surg Oncol 2012;2012:296829.

15. Early Breast Cancer Trialists' Collaborative Group (EBCTCG). Overview of the randomized trials of radiotherapy in ductal carcinoma in situ of the breast. JNCIMonographs 2010;41:162-177.

16. Rakovitch E, Nofech-Mozes S, Hanna W, et al. A population-based validation study of the DCIS Score predicting recurrence risk in individuals treated by breast-conserving surgery alone. Breast Cancer Res Treat 2015;152:389-98.

17. Sagara Y, Freedman RA, Vaz-Luis I, et al. Patient Prognostic Score and Associations With Survival Improvement Offered by Radiotherapy After BreastConserving Surgery for Ductal Carcinoma In Situ: A Population-Based Longitudinal Cohort Study. J Clin Oncol 2016;34:1190-1196.

18. Ceilley E, Jagsi R, Goldberg S, Powell S, Taghian A. The management of ductal carcinoma in situ in North America and Europe. Results of a survey. Cancer 2004;101:1958-1967.

19. McCormick B, Winter K, Hudis C, et al. RTOG 9804: a prospective randomized trial for good-risk ductal carcinoma in situ comparing radiotherapy with observation. J Clin Oncol 2015;33:709-715.

20. ClinicalTrials.gov. Identifier NCT02926911. Comparison of operative to monitoring and endocrine therapy (COMET) trial for low risk DCIS (COMET); 2016 Sep 19. Bethesda (MD): National Library of Medicine (US); 2000.

21. Francis A, Fallowfield L, Rea D. The LORIS trial: addressing overtreatment of ductal carcinoma in situ. Clin Oncol 2015;27:6-8.

22. Elshof LE, Tryfonidis K, Slaets L, et al. Feasibility of a prospective, randomised, open-label, international multicentre, phase III, non-inferiority trial to assess the safety of active surveillance for low risk ductal carcinoma in situeThe LORD study. Eur J Cancer 2015;51:1497-510. 